\title{
Smart irrigation forecast using satellite LANDSAT data and meteo- hydrological modeling
}

\author{
Chiara Corbari $^{\mathrm{a}, *}$, Raffaele Salerno ${ }^{\mathrm{b}}$, Alessandro Ceppi $^{\mathrm{a}}$, Vito Telesca ${ }^{\mathrm{c}}$, Marco Mancini $^{\mathrm{a}}$ \\ a Politecnico di Milano, Milan, Italy \\ ${ }^{\mathrm{b}}$ Meteo Operations Italia - Centro Epson Meteo, Italy \\ ${ }^{\mathrm{c}}$ Università della Basilicata, Potenza, Italy
}

ABSTRACT

The paper discusses advances in coupling satellite driven soil water balance model and meteorological forecast as support for precision smart irrigation use in a case study of an operative farm in the South of Italy where semi-arid climatic conditions holds. Crop water needs forecast are computed with the intuitive idea of forcing the soil water balance model with the meteorological model outlooks. Discussion on the methodology approach is presented, comparing, for a reanalysis period between June and September 2014, the forecast system outputs with observed soil moisture and crop water needs. Two main issues are here in emphasized: the characteristic of soil moisture water balance model, that due to its state variables may be directly calibrated and validated using satellite or near sensing land surface temperatures; the accuracy of those forecast meteorological variables that are the most important in driving the soil water and energy balance. The soil water balance model performances are then discussed highlighting the importance of using a model which state variable (the pixel surface equi-librium temperature) is the same as the data detected by satellite (Land Surface Temperature), so that it can be used for calibrating and validating soil hydrological parameters. Model outputs are also validated with a comparison of ground latent and sensible heat fluxes from an eddy covariance station and soil moisture data. Problems insight into the meteorological modeling, such as temporal and spatial scale, and their influence on soil moisture forecast are discussed showing on the base of several observation periods the need to increase the meteorological forcings accuracy for this type of applications.

The obtained results show how the proposed methodology of the forecasting system is able to have a high reliability in soil moisture forecast correctly providing irrigation suggestion.

Keywords:

Irrigation forecast

Satellite land surface temperature

Meteo-hydrological modelling

\section{Introduction}

Increasing problems of water scarcity indicate the need for a more sustainable approach to water resources management especially in agriculture which is the biggest water consumer: in Europe for around $24 \%$ of the total water use, which reaches the $80 \%$ in the Southern part of Europe (EEA, 2009) and about 50\% in Italy (Zucaro, 2014). Hence, there is the need of operational tools for real-time forecast of irrigation water requirements to promote parsimonious irrigation and a more accurate water management in case of actual or forecasted drought periods, that will result in a mitigation of conflicts in water use among farmers, but also among hydroelectric producers, environmental agencies, tourist activities.

Literature provides several studies on the optimization of irrigation water management starting from the FAO Paper 56 based on crop coefficient (Allen et al., 1998), to water balance modeling and genetic algorithms for optimizing off-farm irrigation scheduling (D'Urso and Menenti, 1995; Roerink et al., 1997; Bastiaanssen et al., 2005; Casa et al., 2009; Ceppi et al., 2014). Different irrigation triggering techni-ques have been developed in literature based on the deficit between potential and actual evapotranspiration or on a soil moisture threshold. The most common approach based on potential ET relies on the methodology proposed by FAO in 1998 (Allen et al., 1998) which uses the PenmanMonteith equation and the crop coefficient (D'Urso and Menenti, 1995). However, Consoli et al. (2014), among others re-searches, showed that even with a deficit irrigation (e.g. $50 \%$ of the potential evapotranspiration), no changes in crop yield are obtained. Allen et al. (1998) suggested that irrigation should be applied when the readily available soil water (RAW) is depleted and irrigate just enough to get back up to field capacity.

\footnotetext{
* Corresponding author.

E-mail address: chiara.corbari@polimi.it (C. Corbari).
} 
In the last years, new studies focus on the coupling of meteorological forecasts and hydrological models for irrigation scheduling, such as the EPIC-PHASE model developed by Cabelguenne et al. (1997), the real-time scheduled irrigations approach in UK by Gowing and Ejieji (2001), the Danish warning system eWarning (Jensen and Thysen, 2003), the real-time forecasts for daily evapotranspiration by (Cai et al., 2007), the PREGI (which is an Italian acronym that means "hydrometeorological forecast for irrigation management") system for irrigation thresholds (Ceppi et al., 2014); the reference evapotranspiration forecast (Pelosi et al., 2016). However, the effect on hydrological soil moisture of meteorological forecasts accuracy for agricultural applications is still an open issue (Venaläinen et al., 2005; Ceppi et al., 2014); while it has been extensively analyzed for flood forecasts (Kitanidis and Bras, 1980; Berthet et al., 2009; Zappa et al., 2011; Pappenberger et al., 2015).

Moreover, thanks to the diffusion of remote sensing data, especially for vegetation monitoring ((Normalized difference vegetation index) NDVI, (Leaf area index) LAI), an increasing number of applications for irrigation management is now available (D'Urso and Menenti, 1995; Bausch, 1995; Roerink et al., 1997; Bastiaanssen et al., 2000; Belmonte et al., 2005; D’Urso et al., 2010; Forrest et al., 2012). However, for real time applications, remote sensing data have some disadvantages due to the fact that are instantaneous in time, sometimes affected by clouds cover in the visible and thermal infrared bands, and also only provide indirect measurement of the variables of interest for water management. So the integration of remote sensing data with distributed hydrological models is needed for operative water management (Su, 2002; Jia et al., 2003; Kustas et al., 2004; Anderson et al., 2012; Corbari et al., 2013).

In the agricultural area, the calibration and validation of distributed hydrological models become more problematic in respect to basin scale studies where parameters calibration relies on the comparison between simulated and observed discharges at the available rivers cross sections (Refsgaard, 1997; Rabuffetti et al., 2008). At local scale, soil water balance models can be calibrated and validated against soil moisture measurements or evapotranspiration data from eddy covariance stations (Corbari et al., 2011; Ingwersen et al., 2011; Cammalleri et al., 2012).

However for large irrigation districts, where ground measurements are not representative and available, some approaches based on multi parameters calibration approach have been developed using remote sensing data recalling the idea of controlling internal model processes and variables can be controlled in each pixel of the domain (e.g. soil moisture (SM), land surface temperature (LST) and evapotranspiration fluxes (ET)) (Franks and Beven, 1999; Crow et al., 2003; Immerzeel and Droogers, 2008; Gutmann and Small, 2010; Corbari and Mancini, 2014; Corbari et al., 2015).

The main objective of this paper is the development of a system for operative irrigation water management based on the coupling of remote sensing data, distributed water-energy hydrological model and meteorological forecasts. Furthermore, two sub-objectives can be identified: i) the energy water balance model calibration using satellite data of land surface temperature, ii) the accuracy of the forecasted meteorological variables and the effects on the hydrological forecast.

Remote sensing data from LANDSAT 8 are used as hydrological model parameters (leaf area index (LAI), fractional vegetation cover (fv), albedo), which are used as inputs to hydrological model, and as model state variable (land surface temperature). The distributed hydrological model, Flash-flood Event-based Spatially-distributed rainfall-runoff Transformation- Energy Water Balance model (FEST-EWB) (Mancini, 1990; Corbari et al., 2011), which is based on the energy and water balance, will be firstly calibrated using LST data from LANDSAT 8. The model will then be applied in real time using meteorological forecasts from WRF (Weather Research and Forecasting-Advanced Research WRF) meteorological model based on 8 ensemble members with $72 \mathrm{~h}$ as the forecast horizon provided by Epson Meteo Centre
(EMC)) model for soil moisture forecasts.

This approach is experimented in an asparagus field in Southern Italy irrigated with drip irrigation where ground measurements of eddy covariance and soil moisture are collected for model calibration and validation. The period of analysis is from November 2013 to September 2014.

\section{Materials and methods}

\subsection{Hydrological model and the calibration procedure based on LST}

FEST-EWB is a distributed hydrological energy water balance model that computes all the main processes of the hydrological cycle in each cell of the domain. A detailed description of the different updates of FEST-EWB model can be found starting from (Mancini, 1990; Corbari et al., 2011, 2013).

FEST-EWB model is based on the system of energy-water balances equations which are written in terms of the LST, so that this model internal variable can be directly compared with remotely sensed LST. The model solves the system between energy and mass balance at the ground surface:

$\left\{\frac{d S M}{d t}=\frac{P+I-R-P E-E T}{d z}\right.$

$\left\{R_{n}-G-H-L E=\frac{d S}{d t}\right.$

where: SM (-) is the soil water content, $\mathrm{P}(\mathrm{mm})$ is the precipitation rate plus the irrigation rate $\mathrm{I}(\mathrm{mm}), \mathrm{R}(\mathrm{mm})$ is the runoff flux, PE $(\mathrm{mm})$ is the drainage flux, ET (mm) is the evapotranspiration, $\mathrm{dz}(\mathrm{mm})$ is the soil depth, $\mathrm{Rn}\left(\mathrm{Wm}^{-2}\right)$ is the net radiation, $\mathrm{G}\left(\mathrm{Wm}^{-2}\right)$ is the soil heat flux, $\mathrm{H}$ $\left(\mathrm{Wm}^{-2}\right)$ is the sensible heat flux, $\mathrm{LE}\left(\mathrm{Wm}^{-2}\right)$ is the latent heat flux, dS/ $\mathrm{dt}$ encloses the energy storage terms, such as the photosynthesis flux and the crop and air enthalpy changes.

In particular ET is linked to the latent heat flux through the latent heat of vaporization $(\lambda)$ and the water density ( $\rho w)$ :

$L E=\lambda \rho_{w} E T$

The latent heat flux is then computed as:

$L E=\frac{\rho_{a} c_{p}}{\gamma}\left(e^{*}-e_{a}\right)\left[\frac{f_{v}}{\left(r_{a}+r_{c}\right)}+\frac{1-f_{v}}{\left(r_{a b s}+r_{s}\right)}\right]$

where $\rho$ a is the air density, $\gamma$ is the psychometric constant $\left(\mathrm{Pa}^{\circ} \mathrm{C}^{-1}\right), \mathrm{f}_{\mathrm{v}}$ is the vegetation fraction and $c_{p}$ is the specific heat of humid air $\left(\mathrm{MJ} \mathrm{kg}^{-1} \mathrm{~K}\right.$ $\left.{ }^{-1}\right)$. The saturation vapour pressure $\left(\mathrm{e}^{*}\right)$ is computed as function of RET while the vapour pressure $\left(e_{a}\right)$ as a function of air temperature. The canopy resistance $\left(r_{c}\right)$ is expressed following (Jarvis, 1976), while the soil resistance $\left(r_{s}\right)$ according to Sun (1982). The aerodynamic resistance ( $r_{a}$ for vegetation and $r_{a b s}$ for bare soil) is computed using the model from Thom (1975).

The energy budget equation is then solved explicitly looking for the representative equilibrium temperature (RET) which is the land surface temperature that closes the energy balance of each pixel. In fact, it includes the heterogeneity of pixel surface, the multi-source emissivity of land surface temperature and the link with the aerodynamic resistance in the turbulent fluxes estimate. So following the proposed approach, LST can be seen as a proxy of soil moisture and thus a key variable in the fluxes estimates.

In particular, the innovative proposed calibration method of the soil hydraulic and vegetation parameters is based on the minimization of the differences, pixel by pixel, between the model RET and the remotely observed LST with a trial and error approach (Corbari and Mancini, 2014; Corbari et al., 2015). This new method improves the actual calibration of distributed hydrologic models which is generally performed by comparison between simulated and available observed discharges at limited river cross sections or few local soil moisture measurements. 

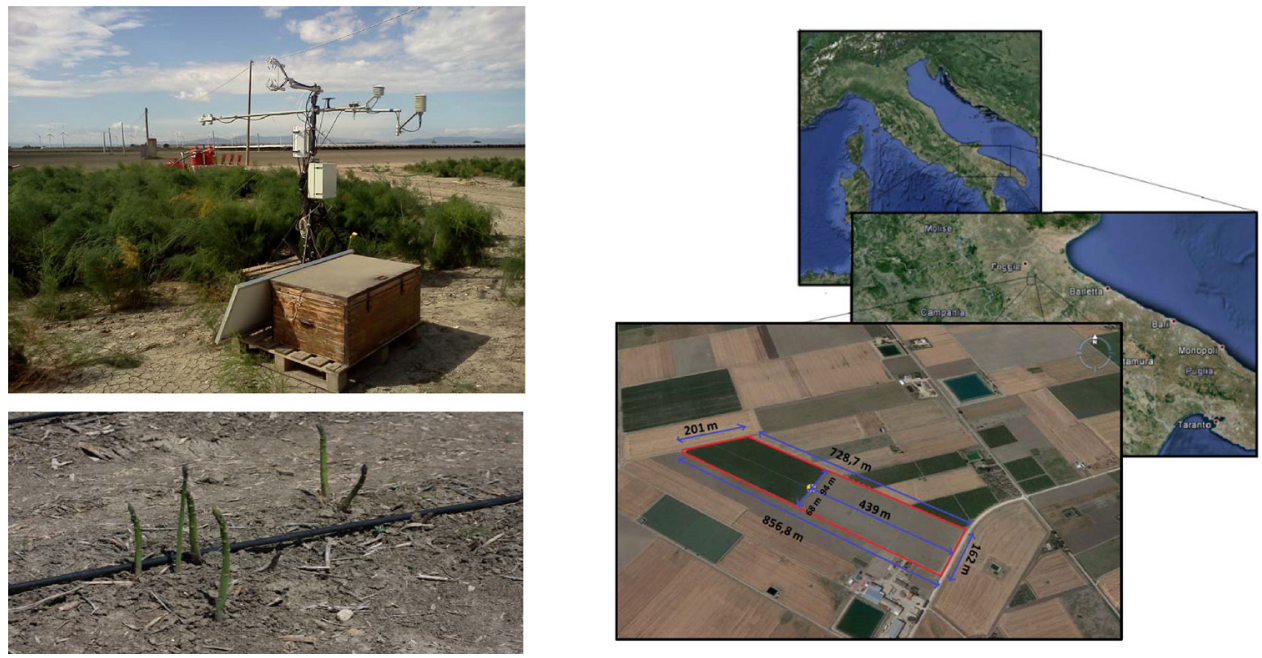

Fig. 1. Location of the area of study in Southern Italy: eddy covariance station installed in the field, drip irrigation system and field dimensions.

This new approach bridges the gap between internal variables of the process modelling (e.g. SM, ET, LST) and external variables (e.g. discharge measurements), problem already highlighted by Dooge (1986) thirty years ago, when he encouraged the hydrologic community to analyse the behaviour of the model internal state variables in addition to the traditional input-output methods.

The model uses as inputs: 1) meteorological variables (historical time series or forecasted data), such as air temperature, incoming shortwave radiation, wind velocity, precipitation, air humidity; 2) soil parameters in distributed maps, such as the saturated hydraulic conductivity, the field capacity (fc) and wilting point (wp), Brooks-Corey index, soil depth, residual and saturated soil moisture; 3) vegetation parameters, such as leaf area index (LAI), vegetation fraction ( $\mathrm{fv}$ ) and albedo from remote sensing and also vegetation height (hv) and minimum stomatal resistance (rsmin); 4) the digital elevation model (DEM) and land use/cover map. Observed ground meteorological data are interpolated to a regular grid using the inverse distance weighting technique.

Irrigation is applied in the model as water applied to the surface contributing to the water budget changes.

FEST-EWB model is run at a spatial resolution of $10 \mathrm{~m}$ and with a time step of an hour.

\subsection{Irrigation water needs forecast procedure}

Irrigation water needs forecast are quantified from the coupled system between the hydrological model fed with satellite data and the meteorological forecasts providing real-time and forecasted soil moisture behavior to trigger irrigation.

The decision criteria in order to plan whether or not to irrigate is based on the comparison between the forecasted soil moisture and a water stress threshold $\left(\theta_{\text {crit }}\right)$ below of which the crop begins to suffer for lack of water. This criterion will determine the correct timing of irrigation and the amount of water. In this paper, the reanalysis of three events is performed simulating a real-time simulation.

The whole procedure is as follow: 1) the hydrological model is run each day with meteorological forecasts for the forecast horizon of $72 \mathrm{~h}$, using as initial conditions: i) the soil water content obtained from FESTEWB simulation run with observed data of the previous days and, ii) the vegetation and albedo parameters from LANDSAT data; 2) the forecasted soil moisture is compared in each pixel at every time step with the stress threshold in order to trigger irrigation; 3 ) every day steps 1 ) and 2) are repeated.

The implemented procedure follows the PREGI system applied by Ceppi et al. (2014), which is here improved with the use of remote sensing data for the definition of the hydrological model initial condition.

This stress threshold, below which vegetation is stressed and irrigation is need, is a function of the different types of soils and crops, but also of the vegetation growth stage and of the climatology of the area of study. The implemented procedure relies on a $\theta_{\text {crit }}$ which is computed following the methodology of Allen et al. (1998) in the FAO-56 paper, based on:

$\mathrm{RAW}=\mathrm{p}$ TAW

where RAW is the readily available water, defined as field capacity minus stress threshold; TAW is the total available water, defined as field capacity minus wilting point; and $\mathrm{p}$ is a reduction coefficient depending on the crop and climatic parameters. For asparagus, $\mathrm{p}$ is defined by Allen et al. (1998) to be equal to 0.45 , which it is then corrected for climatic data to 0.65 following Allen et al. (1998).

Then, $\theta_{\text {crit }}$ for the specific analyzed field, considering the soil characteristics, is computed to be equal to 0.27 from:

$\theta_{\text {crit }}=$ field capacity $-\mathrm{p} \cdot($ field capacity - wilting point $)$

A surplus threshold can also be identified equal to the field capacity of the soil.

\subsection{Case study area}

The area of analysis is an extensive farm located in Southern Italy near Foggia, in a plain area in Tavoliere delle Puglie (Fig. 1). The farm is dedicated to fresh vegetables production for department store distribution. Asparagus, Swiss Chard, Leaf Beet, Savoy Cabbage, Fennel, Spinach among others are cultivated between September and April avoiding the hottest season. In fact, this area has a Mediterranean climate with very hot and dry summer, and temperate winter; so that the area is characterized by water scarcity. Water is withdrawn from the deep aquifer with wells and collected in reservoirs increasing the costs of water. Irrigation is usually performed using drip or sprinkler methods and is only on demand.

The selected field is cultivated with green asparagus with an areal extension of about 13 ha. The asparagus, which is a plurennial cultivation, in the Puglia region is characterized by the harvesting from March to June, developing shrubberies for most of the year and cutting of the shrubberies in January. The period of analysis is from 30 November 2013 to September 2014.

The irrigation is performed with drip irrigation, in order to minimize the water losses. During the analyzed period, three irrigations have been performed: 10 June, 29 July and 24 August 2014. The 
Table 1

Satellite images.

\begin{tabular}{lll}
\hline Satellite & date & Hour $(\mathrm{UTC}+1)$ \\
\hline L8 & 20 December 2013 & $10: 43$ \\
L7 & 7 February 2014 & $10: 32$ \\
L7 & 18 March 2014 & $10: 38$ \\
L8 & 19 March 2014 & $10: 35$ \\
L7 & 2 April 2014 & $10: 32$ \\
L7 & 5 May 2014 & $10: 38$ \\
L8 & 6 May 2014 & $10: 34$ \\
L8 & 22 May 2014 & $10: 34$ \\
L7 & 30 May 2014 & $10: 32$ \\
L8 & 7 June 2014 & $10: 34$ \\
L7 & 22 June 2014 & $10: 38$ \\
L7 & 8 July 2014 & $10: 38$ \\
L8 & 9 July 2014 & $10: 35$ \\
L8 & 16 July 2014 & $10: 41$ \\
L7 & 17 July 2014 & $10: 32$ \\
L8 & 10 August 2014 & $10: 35$ \\
\hline
\end{tabular}

amount of water for each irrigation is fixed at $50 \mathrm{~mm}$.

\subsubsection{Soil hydraulic properties}

Soil pedologic characteristics are available from the granulometric analysis done on soil samples taken from the field at 5,10 and $30 \mathrm{~cm}$. The soil contains $58 \%$ clay, $25.1 \%$ sand and $16.9 \%$ loam and can be classified as clay soil based on soil texture triangle (Saxton et al., 1986). From this data, hydraulic soil parameters required for the application of the hydrological model have been derived using the well-known database of Rawls and Brakensiek (1985). The mean value of the clay class is then used as first tentative before the calibration: saturated hydraulic conductivity $=1.110^{-7} \mathrm{~m} \mathrm{~s}^{-1}$, the field capacity $=0.396$, wilting point $=0.272$, Brooks-Corey index $=0.165$, residual and saturated soil moisture ( 0.09 and 0.48 respectively).

\subsection{Ground eddy covariance data}

The asparagus field is monitored with a complete eddy covariance station (Fig. 1). This is equipped with different sensors to measure the principal mass and energy fluxes, such as net radiation, evapotranspiration, sensible and ground heat fluxes, soil temperature, land surface temperature and soil moisture; and also to measure the principal meteorological forcings (air temperature and relative humidity, wind velocity, precipitation and incoming shortwave radiation). The station is equipped with: a coupled 3D sonic anemometer and gas analyzer (Campbell Scientific's IRGASON) at $3 \mathrm{~m}$ height, a net radiometer (CNR1 by Kipp and Zonen) at $3 \mathrm{~m}$ height, a thermo-hygrometer and pluviometer; while in the soil a Time domain Reflectomer probe, two thermocouples and a heat flux plate (HFP01 by Hukseflux).

The eddy covariance station has been installed on 7 November 2013 and the analyzed data are available till 2 September 2014. Data are stored at high frequency and are available, after all the post-processing procedure, at $30 \mathrm{~min}$

Turbulent energy fluxes have been corrected applying the whole range of correction procedures which are now well assessed in the scientific community (Foken, 2008). The data are analyzed with the PEC software (Polimi Eddy Covariance) (Corbari et al., 2012) which encompasses all the instrumental and physical corrections. Corbari et al. (2012), compared corrected fluxes at high frequency data and at $30 \mathrm{~min}$ average data showing that low errors can be obtained with mean absolute daily difference equal to $6.1 \mathrm{~W} \mathrm{~m}^{-2}$ for $\mathrm{H}$ and $13.2 \mathrm{~W} \mathrm{~m}^{-2}$ for LE.

Due to the field dimension (Fig. 1), the footprint analysis of the turbulent fluxes is needed to correctly consider the fluxes measured only in the analyzed field. The footprint of a turbulent flux is the source area of the measured vertical flux and it can be estimated with different theoretical models. In this study, a two-dimensional footprint model is used (Detto et al., 2006) based on the original one-dimensional model of Hsieh et al. (2000).

After the whole correction procedure with PEC and the footprint analysis, about the $43 \%$ of the data have been discarded (Foken, 2008).

The energy budget closure has also been analyzed and an angular coefficient $((\mathrm{Rn}-\mathrm{G})=\mathrm{m}(\mathrm{H}+\mathrm{LE}))$ of 0.97 with a $\mathrm{R}^{2}$ of 0.78 is obtained. A general lack of energy balance closure in eddy covariance measurements is a well-known problem in literature, with values of the closure ranging between 0.6 and 0.8 (Foken, 2008).

For the calibration / validation of the energy water balance model, which is intrinsically based on the conservation of energy, the observed energy budget closure should be kept. So, following the procedure developed by Twine et al. (2000), latent and sensible heat fluxes, which usually underestimate the available energy when measured with the eddy covariance technique, are corrected respecting the Bowen-ratio method to reach the energy balance closure.

Meteorological forcings for the FEST-EWB model are also taken from the station in terms of air temperature and relative humidity, wind velocity, precipitation and incoming shortwave radiation.

\subsection{Satellite landsat 7 and landsat 8 data}

NASA images from the Landsat 8 Operational Land Imager (OLI) and Thermal Infrared Sensor (TIRS) and Landsat 7 are used to retrieved land surface temperature as well vegetation parameters and albedo. A spatial resolution of $30 \mathrm{~m}$ is available for the visible bands while $100 \mathrm{~m}$ in the thermal infrared ones; while the temporal resolution is of 16 days. The data in the visible range of the electromagnetic spectrum are atmospherically corrected using the FLASH method (Matthew et al., 2000), while thermal data with the method developed by Barsi et al. (2005) (http://atmcorr.gsfc.nasa.gov/). The images are selected during the analyzed period from December 2013 to the end of August 2014 considering only clear sky days. The dates are reported in Table 1.

The vegetation information from satellite data, needed as input parameters to the hydrological model, are the vegetation fraction, leaf area index and albedo.

LAI and $\mathrm{fv}$ are computed following the algorithms developed by Richter and Timmermans (2009), which estimates LAI as a function of NDVI:

$L A I=-\frac{\log \left(1-\left(\frac{N D V I}{0.95}\right)\right)}{0.75}$

and the vegetation fraction based on LAI:

$f_{v}=1-\exp (-0.5 L A I)$

NDVI maps have been retrieved from the ratio between NIR-RED over NIR + RED, where RED is the spectral reflectance measured in the red region of the electromagnetic spectrum and NIR in the near-infrared region.

Albedo is computed following Liang (2000) for Landsat 7 images and Ke et al. (2016) for Landsat 8 images.

Land surface temperature, which is used for FEST-EWB model calibration, is retrieved from Landsat 7 and 8 thermal infrared bands, using a single channel algorithm developed by Jiménez-Muñoz et al. (2009).

\subsection{Meteorological forecasts}

Meteorological forecasts are obtained from the Weather Research and Forecasting-Advanced Research (ARW-WRF) meteorological model of NCAR (National Center of Atmospheric Research), and are provided by Epson Meteo Centre (Italy).

The model provides all the meteorological forcings needed to the hydrological model: rainfall, air temperature and humidity at $2 \mathrm{~m}$, wind speed at $10 \mathrm{~m}$ and incoming shortwave radiation. 
The spatial resolution is of $0.03^{\circ}$ covering the whole area around Foggia city. This high spatial resolution is obtained through a nesting: initial and boundary conditions are provided by the global Global Forecast System (GFS) over the whole italian area with a spatial resolution of $12 \mathrm{~km}$. Inside this, a domain area of the Southern Italy at $3 \mathrm{~km}$ of spatial resolution with 37 vertical levels. The model version of this study produces a probabilistic forecast with 8 ensembles. When running operatively, the simulations are initialized every day at 00:00 UTC and the forecast horizon is equal to $72 \mathrm{~h}$. The meteorological forecasts are then at hourly scale.

The considered events coincide with the three irrigations performed during the 2014 season. For the June event the meteorological model is initialized on 7, 8, 9 and 10 June; for the July event on 26, 27, 28 and 29 July; for the August event on 21, 22, 23 and 24 August 2014.

\subsection{Statistical indexes}

Different statistical indexes are computed to evaluate the goodness of hydrological model estimates in terms of RET, soil moisture and energy fluxes. So the absolute mean bias error (AMBE) and the root mean square error (RMSE) are computed as follows:

$A M B E=\frac{\sum_{i=1}^{n}\left|X_{s i m}^{i}-X_{o b s}^{i}\right|}{n}$

$R M S E=\left[\frac{\sum_{i=1}^{n}\left(X_{\text {sim }}^{i}-X_{o b s}^{i}\right)^{2}}{n}\right]^{0.5}$

where $\mathrm{X}_{\text {sim }}{ }^{\text {ith }}$ is the ith simulated variable by FEST-EWB, $\mathrm{X}_{\mathrm{obs}}{ }^{\text {ith }}$ is the ith measured variable, $\mathrm{n}$ the sample size, and $\overline{X_{o b s}}$ the average observed variable. The simulated and observed variables are always relative to the same variable, so that if RET, for example, is computed for LST, $\mathrm{X}_{\mathrm{sim}}, \mathrm{X}_{\mathrm{obs}}$ and $\overline{X_{o b s}}$ are all land surface temperature values.

The absolute $\left(\varepsilon_{\text {ass }}\right)$ and relative $\left(\varepsilon_{\text {rel }}\right)$ errors of forecasted meteorological and hydrological outputs are computed considering the ensembles, as follow:

$\varepsilon_{a s s}(\Delta t)=\mu\left[\frac{1}{t} \sum_{t=1}^{\Delta t}\left[\left(\frac{1}{n} \sum_{i=1}^{n} x_{i}\right)-y\right]\right]$

$\varepsilon_{\text {rel }}=\frac{\varepsilon_{\text {ass }}}{\mu(y)} 100$

where $\mathrm{x}$ is the simulated variable and $\mathrm{y}$ the observed one, $\mu$ is the mean operator, $\mathrm{n}$ is the ensembles number.

\section{Results}

\subsection{Satellite data retrieval and validation}

Vegetation parameters are retrieved from Landsat 7 and 8 for the considered period using the available non cloudy images. In Fig. 2(a), the seasonal dynamic of vegetation is reported showing the variability of LAI, NDVI and vegetation fraction. The mean value of the analyzed field is reported. Unfortunately, no ground data of these parameters have been collected to validate satellite data. However, at least, the periods of bare soil and vegetation are correctly reproduced, where from January 2014 till the end of March 2016 there is no vegetation at all, while during April 2016 till the half of May only the asparagus is present, and from the end of May to September the asparagus shrubbery are present.

The accuracy of remote sensing albedo is evaluated against the ground data measured in continuous at the eddy covariance station by the net radiometer. In Fig. 2(b), the mean satellite albedo value of the field is reported showing a good correspondence with ground measurements. An AMBE of 0.014 and a RMSE of 0.02 are obtained confirming the good estimates from satellite data.
The reliability of satellite LST estimates is analyzed by comparison with ground measurements performed at the eddy covariance station. In Fig. 3, the mean areal estimates from Landsat 7 and Landsat 8 are reported leading globally to an AMBE value of $1.85^{\circ} \mathrm{C}$ and a RMSE of 2.5 ${ }^{\circ} \mathrm{C}$. If the linear regression between ground $(\mathrm{y})$ and satellite data $(\mathrm{x})$ is computed, an angular coefficient of 1.01 is obtained with $\mathrm{R}^{2}$ of 0.9 .

\subsection{Hydrological model calibration and validation}

The calibration of soil hydraulic and vegetation parameters is performed through the comparison between RET estimates from FEST-EWB run in different parameters configurations and LST from Landsat data. With a trial and error approach, the parameters are modified from the original values minimizing the difference pixel by pixel between observed LST and simulated RET. The parameters are modified in the physical ranges defined by Rawls and Brakensiek (1985). The FEST-EWB configuration is simplified without computing surface and sub-surface discharges and without snow dynamics which are considered not relevant for the area of interest.

The calibration/validation period is from 30 November 2013 to September 2014. The model is initialized on 30 November 2013 with the observed ground SM.

The differences between LST from Landsat and RET for each date are computed iteratively during the calibration process. FEST-EWB with the original soil / vegetation parameters before calibration generally overestimates observed satellite values. In Fig. 4(a) the field areal mean value of FEST-EWB land surface temperature estimates and satellite LST are reported. RMSE is equal to $5.12{ }^{\circ} \mathrm{C}$ and AMBE to $4.32{ }^{\circ} \mathrm{C}$. After the calibration procedure, a reasonable agreement between RET and Landsat LST is reached with RMSE of $1.8^{\circ} \mathrm{C}$ and AMBE of $1.9^{\circ} \mathrm{C}$.

After the calibration procedure the soil parameters are: saturated hydraulic conductivity $=1.810^{-7} \mathrm{~m} \mathrm{~s}^{-1}$, the field capacity $=0.396$, wilting point $=0.272$, residual and saturated soil moisture $(0.09$ and 0.48 respectively). Controllare congruenza

After the calibration process, RET estimates from FEST-EWB are compared with the continuous in time LST ground data and a RMSE of $2.5{ }^{\circ} \mathrm{C}$ and AMBE of $2.1{ }^{\circ} \mathrm{C}$ are obtained. In Fig. 4(b), the scatterplot between calibrated RET and ground LST for the whole period is reported showing the good agreement with $\mathrm{R}^{2}$ of 0.96 and the angular coefficient of the linear regression forced through the origin between RET (x) and LST from the station (y) equal to 0.96. These results indicate the general good ability of the model in reproducing the seasonal variability and the daily cycle of land surface temperature, even though with higher errors than against satellite data.

FEST-EWB model is then validated for the same period by comparing the simulated energy and water fluxes (LE, SM, H, Rn) with the observed ones. In fact, changes in soil hydraulic and vegetation parameters lead to modifications not only in the representative equilibrium temperature but also in its interconnected variables, such as soil moisture and evapotranspiration. The measured fluxes are compared with the simulated ones before and after the calibration process showing the good accuracy reached at the end of the procedure. Soil moisture is correctly reproduced with a RMSE of 0.04 (Fig. 5(a)). However, SM observations have a dramatically strong decrease around the 9 of June due to a prolonged drought period which caused cracks in the soil, which are not modeled by FEST-EWB. Fig. 5(b) shows the model performances in terms of net radiation. The agreement is good, with the coefficient of determination being 0.86 , the angular coefficient 0.95 , the RMSE $20.9 \mathrm{~W} \mathrm{~m}^{-2}$. Good reproductions are obtained also for the surface sensible and latent heat fluxes, as shown in Fig. 5(c) and (d). The agreement is in confirmed for LE by a coefficient of determination equal to 0.85 and a RMSE of $33.3 \mathrm{~W} \mathrm{~m}^{-2}$, while for $\mathrm{H}$ with $\mathrm{R}^{2}$ of 0.76 and RMSE of $32.7 \mathrm{~W} \mathrm{~m}^{-2}$. 

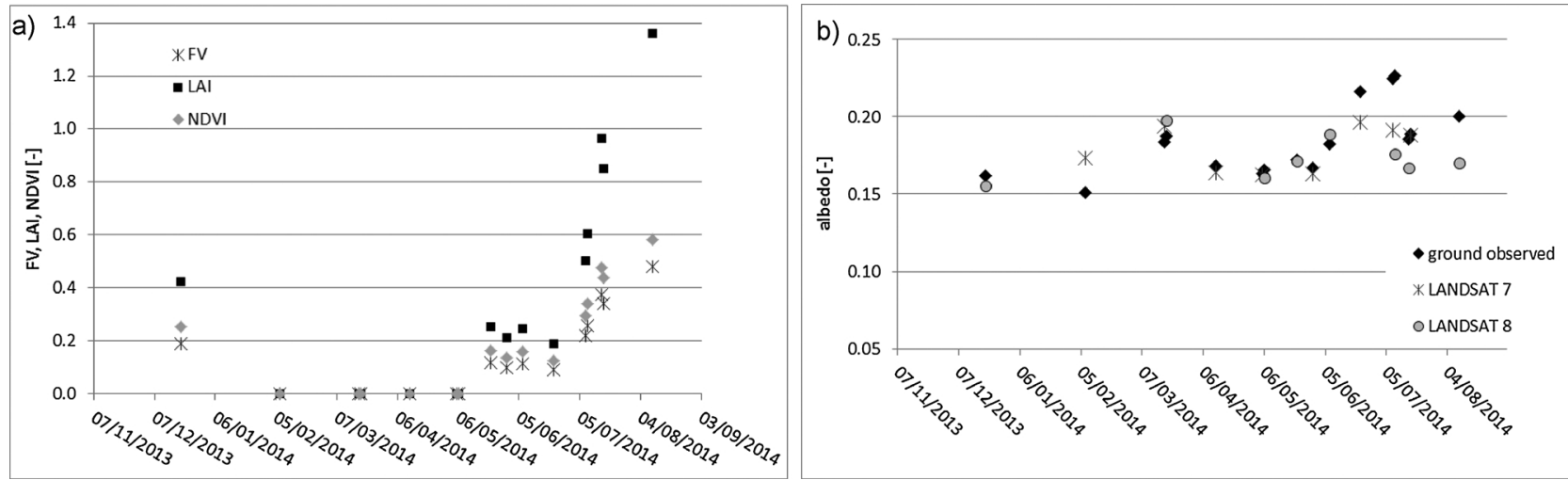

Fig. 2. Areal mean of the vegetation parameters (LAI, vegetation fraction and NDVI) (a) and albedo (b) retrieved from LANDSAT 8 / 7 for the satellite acquisition dates in the analyzed period over the asparagus field.

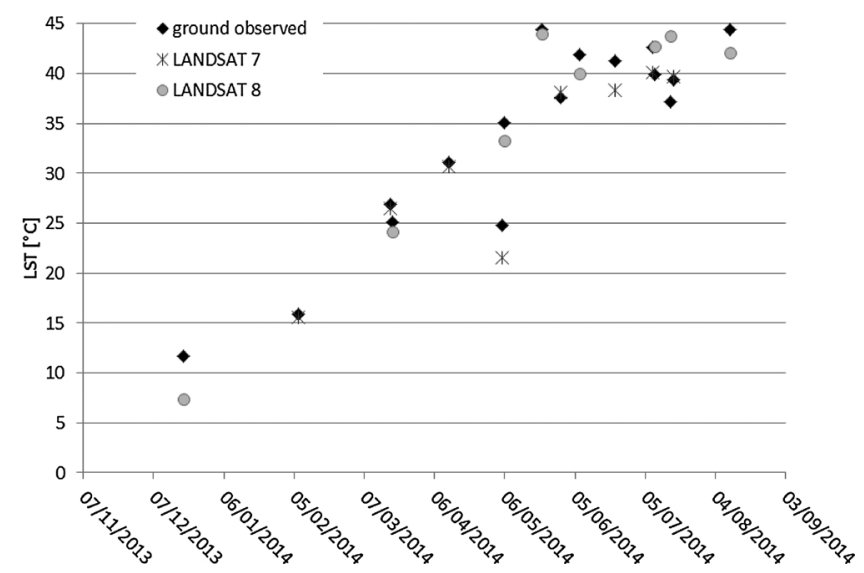

Fig. 3. Comparison between the areal mean of LST retrieved from LANDSAT 8 / 7 and ground data for the satellite acquisition dates in the analyzed period over the asparagus field.

\subsection{Irrigation water needs forecast}

Following the procedure described in paragraph 2.2, forecasted irrigation water needs are quantified from the coupled system between the hydrological model fed with satellite data and the meteorological forecasts for the reanalysis periods of the three selected irrigation events.

In this paragraph the reliability of the meteorological model is at first evaluated and then its impact on the hydrological simulations is analyzed.

\subsubsection{Meteorological forecasts reliability}

The reliability of the meteorological forecasts is evaluated for all the three considered periods of analysis by comparison with the observed data in the studied area, computing $\varepsilon_{\text {ass }}$ and $\varepsilon_{\text {rel }}$ from Eq. (11) and (12).

As example, Fig. 6 reports for the ensemble forecasts of 26, 27, 28 and 29 July 2014 for the next $72 \mathrm{~h}$, the observed variable and the eight modeled ensembles in terms of air temperature and humidity, incoming shortwave radiation, precipitation and wind speed. A not consistent performance for all the meteorological forecasts is achieved. In fact, air temperature differences for the July analysis have a mean value of $2.4^{\circ} \mathrm{C}$ which is a quite restrained error in terms of meteorological forecast. The spread of the eight ensembles is equal to $2.3{ }^{\circ} \mathrm{C}$. However, during the central diurnal hours of the day, the errors are considerably higher reaching a mean value of $3{ }^{\circ} \mathrm{C}$. This discrepancy can have a strong impact on latent heat flux and soil moisture estimates from FEST-EWB model. Going more in the details of the comparison between ob-served and forecasted air temperature considering the different forecast horizons, the forecast reliability doesn't tend to diminish by increasing the forecast horizon as usually expected (17). In fact, the errors computed for the first days of forecast for all the July dates, $\varepsilon_{\text {ass }}$ is equal to $2.7^{\circ} \mathrm{C}$, decreasing to $2.4{ }^{\circ} \mathrm{C}$ for the second days of forecast and to $2.1{ }^{\circ} \mathrm{C}$ for the third days. Generally, for the whole analyzed periods, air temperature behaves similarly to the afore described July dates analyses, even with lower mean differences between forecasted and observed Ta equal to $1.2{ }^{\circ} \mathrm{C}$ for June and to $1.7{ }^{\circ} \mathrm{C}$ for August but with still higher discrepancies in the central diurnal hours of the day are obtained with mean error values around $3.5^{\circ} \mathrm{C}$.

The incoming shortwave radiation errors (Fig. 6) during July follow the behavior of Ta with a mean $\varepsilon_{\text {ass }}$ around $103 \mathrm{~W} \mathrm{m-2} \mathrm{but} \mathrm{with} \mathrm{peaks}$
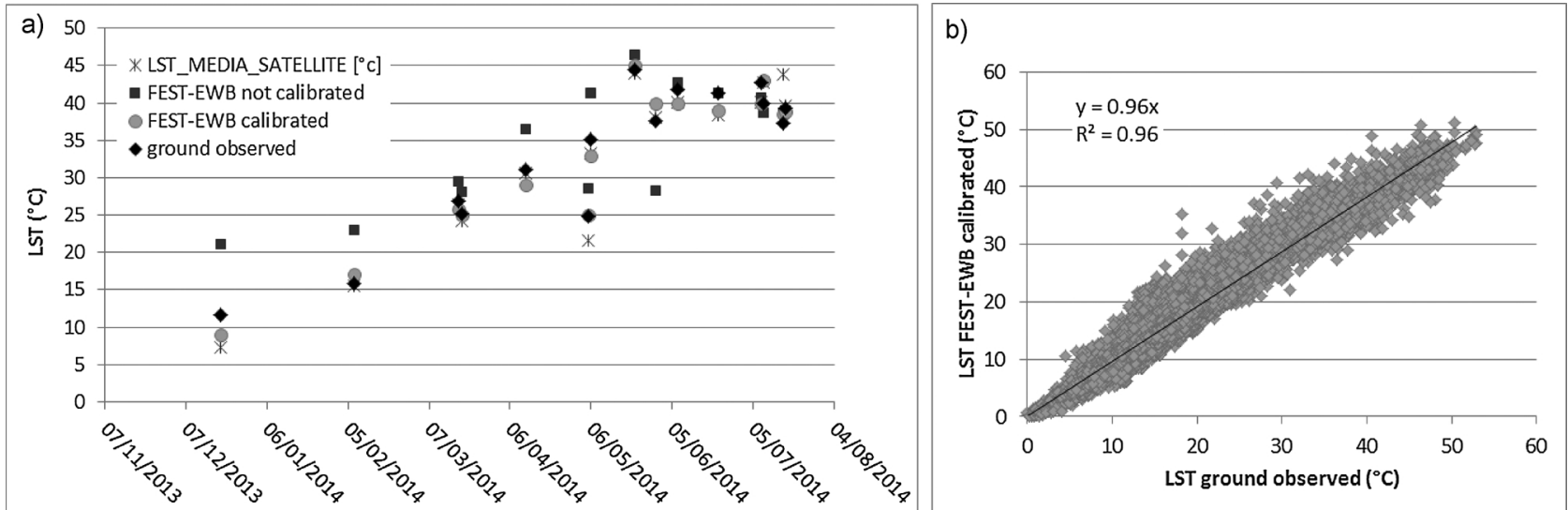

Fig. 4. (a) Comparison between calibrated and not calibrated RET from FEST-EWB and LST from Landsat and ground observation for the satellite acquisition dates, (b) scatterplot between calibrated RET and ground LST for the whole analyzed period. 

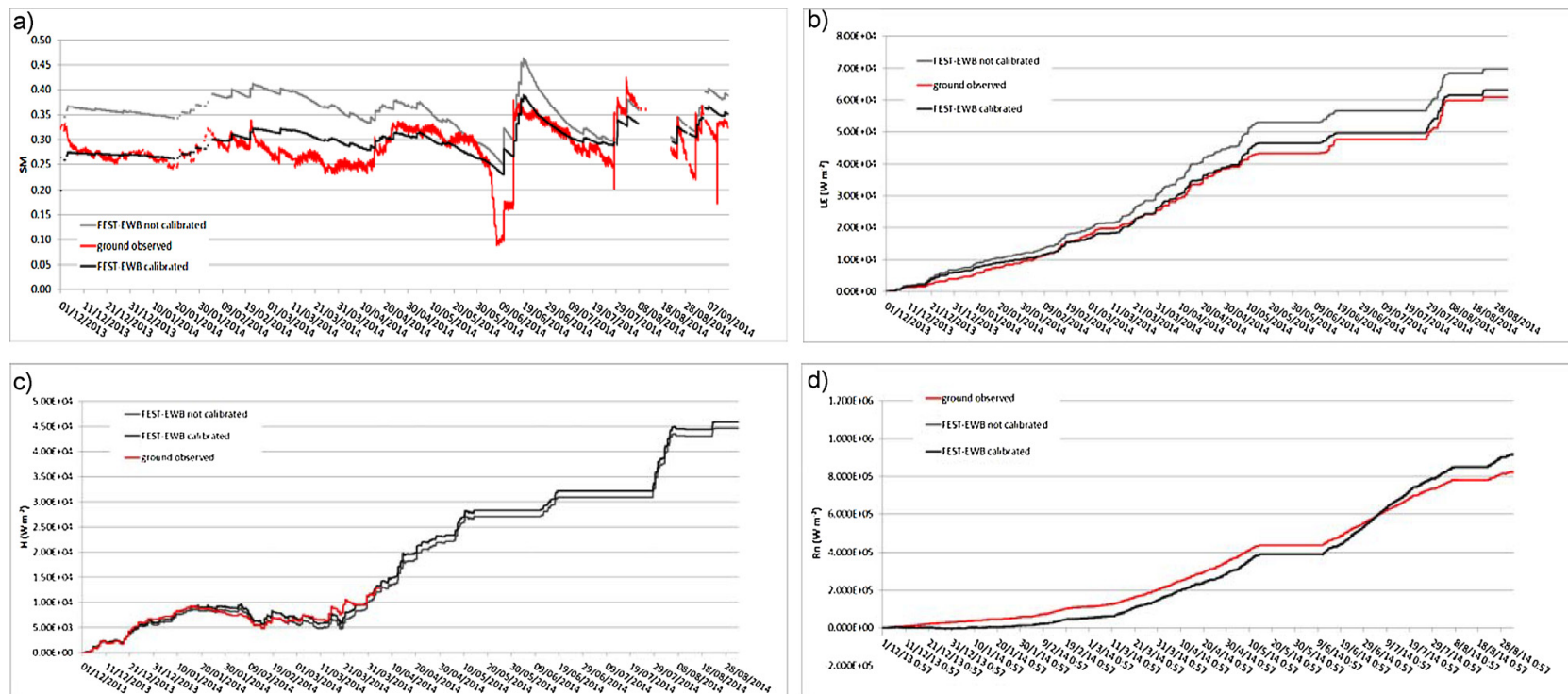

Fig. 5. Comparison between energy fluxes and soil moisture from FEST-EWB before and after the calibration and ground measurements: (a) soil moisture, (b) net radiation, c) latent heat flux, (d) sensible heat flux, for the whole analyzed period.

during the central hours of the days reaching $170 \mathrm{~W} \mathrm{~m}-2$. The forecast time horizon seems to not affect the forecast reliability with $\varepsilon_{\text {ass }}$ of $96 \mathrm{~W}$ $\mathrm{m}-2,100 \mathrm{~W} \mathrm{~m}-2,88 \mathrm{~W} \mathrm{~m}-2$, respectively for the first, second and third days of forecast. Particularly high values are found due to local clouds conditions which are difficulty modeled at the spatial resolution of a meteorological model.

The air relative humidity has an almost constant mean error over the different days of forecast equal to $0.15 \%$. The wind velocity has $\varepsilon_{\text {ass }}$
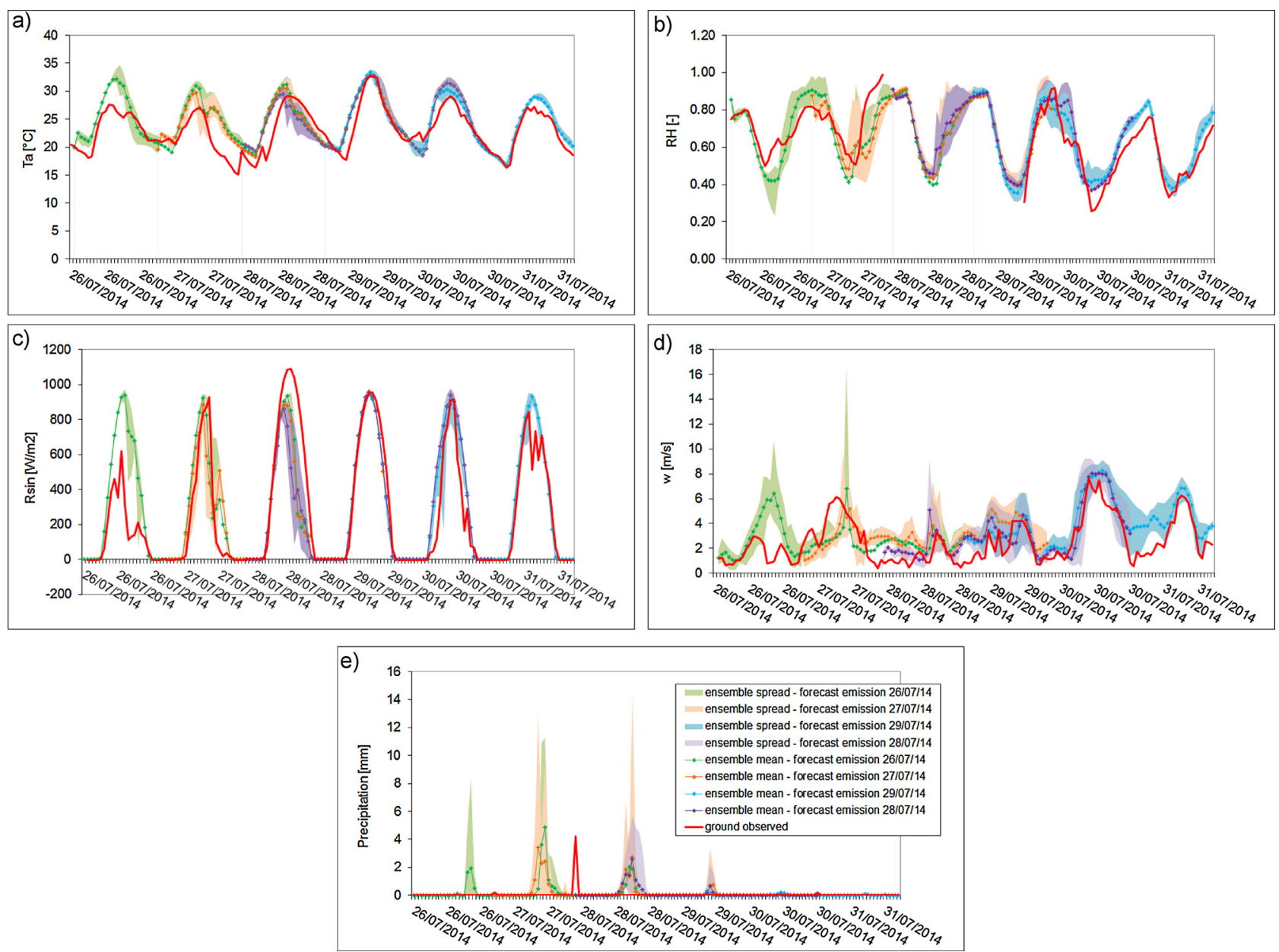

Fig. 6. Comparison between observed ground meteorological forcings and ensemble forecasts for the event from 26 to 31 July 2014: (a) air temperature, (b) relative humidity, (c) incoming shortwave radiation, (d) wind speed, (e) precipitation. The forecast emissions of 26, 27, 28 and 29 July are shown. 
Table 2

Statistical errors of meteorological forecasts.

\begin{tabular}{|c|c|c|c|c|c|c|}
\hline & & $\varepsilon_{\text {ass }}$ Ta $\left({ }^{\circ} \mathrm{C}\right)\left(\varepsilon_{\text {rel }}(\%)\right)$ & $\varepsilon_{\text {ass }} \operatorname{Rsin}(\mathrm{W} \mathrm{m}-2)\left(\varepsilon_{\mathrm{rel}}(\%)\right)$ & $\varepsilon_{\text {ass }}$ RH (-) $\left(\varepsilon_{\text {rel }}(\%)\right)$ & $\varepsilon_{\text {ass }} \mathrm{W}(\mathrm{m} \mathrm{s}-1)\left(\varepsilon_{\mathrm{rel}}(\%)\right)$ & $\varepsilon_{\text {ass }} \mathrm{P}(\mathrm{mm})\left(\varepsilon_{\text {rel }}(\%)\right)$ \\
\hline \multirow[t]{4}{*}{7 - 12 June 2014} & All the period & $1.18(4.7)$ & $58.5(18)$ & $0.09(20.7)$ & $1.2(33)$ & $0(-)$ \\
\hline & I days of forecast & 1.21 & 57.1 & 0.09 & 0.94 & 0 \\
\hline & II days of forecast & 1.24 & 59.3 & 0.09 & 1.13 & 0 \\
\hline & III days of forecast & 1.11 & 62.1 & 0.08 & 1.36 & 0 \\
\hline \multirow[t]{4}{*}{26 - 31 July 2014} & All the period & $2.37(10.1)$ & $103(35)$ & $0.15(23)$ & $1.4(58)$ & $0.21(7)$ \\
\hline & I days of forecast & 2.7 & 132.3 & 0.15 & 1.37 & 0.27 \\
\hline & II days of forecast & 2.46 & 96.3 & 0.15 & 1.44 & 0.25 \\
\hline & III days of forecast & 2.06 & 88.3 & 0.14 & 1.41 & 0.12 \\
\hline \multirow[t]{4}{*}{21 - 26 August 2014} & All the period & $1.51(5.9)$ & $55.3(20)$ & $0.12(23)$ & $1.7(58)$ & $0.04(2)$ \\
\hline & I days of forecast & 1.8 & 59.3 & 0.12 & 1.76 & 0.07 \\
\hline & II days of forecast & 1.46 & 58.1 & 0.12 & 1.62 & 0.03 \\
\hline & III days of forecast & 1.34 & 51.5 & 0.12 & 1.66 & 0.02 \\
\hline
\end{tabular}

equal to $1.4 \mathrm{~m} \mathrm{~s}-1$, even though with a high variance of around $0.9 \mathrm{~m} \mathrm{~s}$ 1. RH and w seems to be not affected by the daily diurnal cycle.

Precipitation occurred only during the analyzed days during July and August, with a mean $\varepsilon_{\text {ass }}$ equal to 0.21 and $0.4 \mathrm{~mm}$, respectively.

All the statistical errors are summarized in Table. 2 considering the events of June, July and August. The three periods are consistent with similar behaviors. The agreement is generally good for Ta with a mean $\varepsilon_{\text {rel }}$ of $6.9 \%$, while Rsin, RH and w liable to be inconsistent with observations with a mean $\varepsilon_{\text {rel }}$ of respectively $24 \%, 66.7 \%$ and $49.6 \%$. Results concerning precipitation are not considered reliable due to substantial no precipitation during the three analyzed events.

\subsubsection{Soil moisture forecast}

The calibrated hydrological model is then run with meteorological forecasts for the three events of June, July and August to produce ensembles forecasts of soil moisture, latent and sensible heat fluxes.

As example, in Fig. 7, the ensemble forecasts initialized on 26, 27, 28 and 29 July 2014 for the next $72 \mathrm{~h}$ are reported for the eight FEST-EWB modeled ensembles in terms of soil moisture, $\mathrm{LE}$ and $\mathrm{H}$ and the same variables simulated by FEST-EWB using observed meteorological forcings. This comparison allows computing only the effect of the meteorological errors on the hydrological forecasts (without the hydrological model uncertainties) and how they are propagated into the
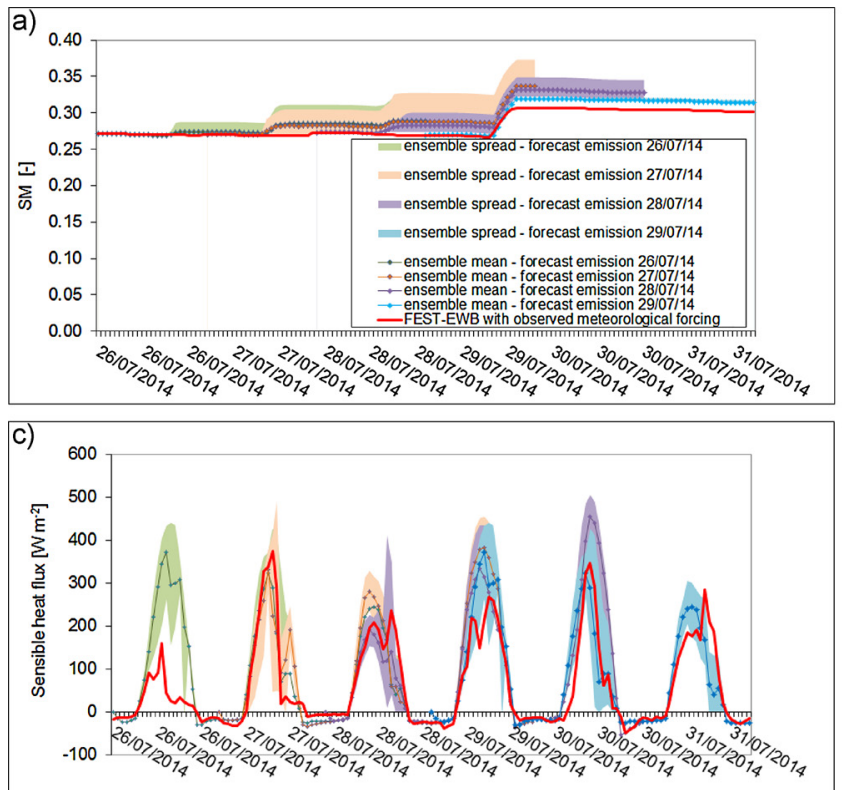

models chain. Latent and sensible heat fluxes estimates have mean discrepancies of respectively $24.6 \mathrm{~W} \mathrm{~m}^{-2}\left(\varepsilon_{\text {rel }} 42 \%\right)$ and $49 \mathrm{~W} \mathrm{~m}^{-2}\left(\varepsilon_{\text {rel }}\right.$ $77 \%)$. In particular, these errors are enhanced during the central diurnal hours of the day, where the differences reach $100 \mathrm{~W} \mathrm{~m}^{-2}$ for LE and 150 $\mathrm{W} \mathrm{m}{ }^{-2}$ for $\mathrm{H}$. This behavior is related to the high errors of the forecasted air temperature and incoming shortwave radiation during the central diurnal hours. The spread of ensembles forecasts of $\mathrm{H}$ and LE are 83 and $33 \mathrm{~W} \mathrm{~m}-2$ respectively, reaching values of 193 and $69 \mathrm{~W} \mathrm{~m}-2$ between 10 a.m. and $3 \mathrm{pm}$ during the day. These hours of the day are mostly affecting water stress.

LST behavior follows energy fluxes dynamics with $\varepsilon_{\text {ass }}$ equal to $6.2{ }^{\circ} \mathrm{C}$ and the ensemble spreads to $4.2^{\circ} \mathrm{C}$.

Soil moisture forecasts seems to be less affected by the meteorological forecasts discrepancies of Ta and Rsin than the latent and sensible heat fluxes, with a mean $\varepsilon_{\text {rel }}$ over the whole analyzed July period equal to $10.2 \%$ and $\varepsilon_{\text {ass }}$ to 0.03 . SM is instead more and directly affected by differences in precipitation forecasts, as shown in Fig. 7 where SM dynamic changes when precipitation occurs (Fig. 6). The spread of SM ensembles forecasts is equal to 0.03 .

All the statistical errors are summarized in Table 3 considering the events of June, July and August. The three periods are consistent between each others with similar behaviors, showing high errors on LE and $\mathrm{H}$ estimates and small errors on SM.
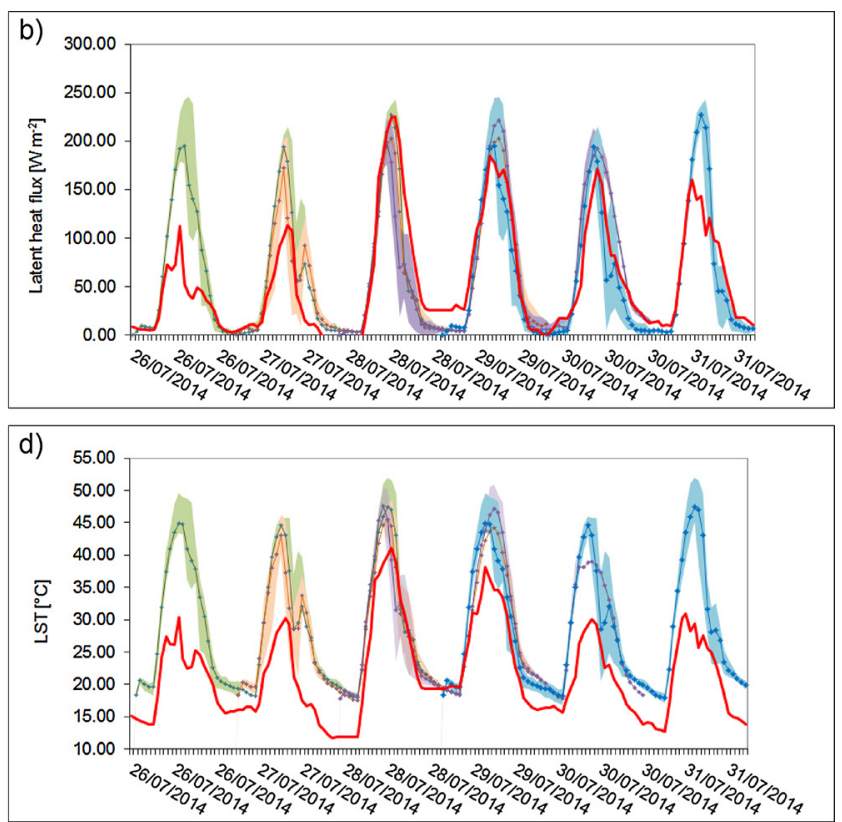

Fig. 7. Comparison between SM, LE, H and RET simulated from FEST-EWB run with observed meteorological forcings and with the ensemble forecasts for the event from 26 to 31 July 2014: (a) soil moisture, (b) latent heat flux, (c) sensible heat flux, (d) land surface temperature. The forecast emissions of 26, 27, 28 and 29 July are shown. 
Table 3

Statistical errors of SM, LE and $\mathrm{H}$ forecasts from FEST-EWB.

\begin{tabular}{|c|c|c|c|c|}
\hline & & $\begin{array}{l}\varepsilon_{\text {ass }} \text { SM (-) } \\
\left(\varepsilon_{\text {rel }}(\%)\right)\end{array}$ & $\begin{array}{l}\varepsilon_{\text {ass }} \text { LE }(\mathrm{W} \text { m-2) } \\
\left(\varepsilon_{\text {rel }}(\%)\right)\end{array}$ & $\begin{array}{l}\varepsilon_{\text {ass }} H(-)\left(\varepsilon_{\text {rel }}\right. \\
(\%))\end{array}$ \\
\hline 7 - 12 June 2014 & $\begin{array}{l}\text { All the } \\
\text { period }\end{array}$ & $0.03(9.7)$ & $23.2(25.2)$ & $50.4(73.4)$ \\
\hline 26 - 31 July 2014 & $\begin{array}{l}\text { All the } \\
\text { period }\end{array}$ & $0.03(10)$ & $24.9(41)$ & $50(77.2)$ \\
\hline $\begin{array}{c}21-26 \text { August } \\
2014\end{array}$ & $\begin{array}{l}\text { All the } \\
\text { period }\end{array}$ & $0.02(8.1)$ & 50.4 (207) & $55.5(99.8)$ \\
\hline
\end{tabular}

Into the hydrological model, as expected, due to its high non linearity, the meteorological forcings errors are not linearly propagated. In fact, the energy fluxes and LST estimates are strongly affected by the differences between meteorological forecasts and observations due to their instantaneous response to external forcings. Instead, soil moisture, which has a slow dynamic especially during dry periods, doesn't have a daily cycle resulting less affected by meteorological forcings variability. This is particularly true over short periods of analysis, as in this paper where only seven days are considered. An immediate effect on SM is visible only when precipitation is forecasted.

\subsection{Irrigation scheduling}

FEST-EWB model is then run for the three reanalysis periods in the real time configuration, in order to understand the reliability of the whole developed methodology for water savings. Hence, to demonstrate the benefits of the methodology based on coupled hydro- meteorological system, two types of simulation are compared: 1) the farmer follows the advice provided by the satellite-hydro-meteorological forecasts knowing with $72 \mathrm{~h}$ in advance if the stress threshold is overpassed and the irrigation is needed (e.g. smart irrigation), and 2) the farmer performs the irrigation based on its own experience (e.g. simulation with observed meteorological and irrigation data).

Fig. 8 shows how the soil moisture conditions would have evolved following or not the meteo-hydrological forecasts between 7-12 June 2014. In particular, the forecasted soil moistures with the two types of irrigation are reported as the mean of the 8 ensembles, together with the stress and surplus thresholds and the wilting point. The FEST-EWB simulation, under the assumption that no irrigation occurred, is included as well. According to the forecast of the 7 June shown in Fig. 8(a), SM goes below the irrigation threshold at the beginning of 9 June, hence the smart irrigation is triggered. The forecasts of the fol-lowing days confirm the need of the irrigation since soil moisture otherwise would have been continuously lying below the stress threshold since no significant rainfall was predicted. The meteo-hy-drological system performed well without consequent high risk of compromising the crops.

In Fig. 9, the forecasted ensembles mean of SM for the event of 26-29 July is shown together with the ensembles mean of the pre-cipitation forecast. SM initial condition on 26 July is slightly over the irrigation threshold, while the SM simulated with observed meteor-ological data slightly falls below the threshold on 27 July. The soil moisture forecasts issued on 26,27 and 28 July confirm a SM constantly above the stress threshold due to a forecasted rainfall. Only with the simulation initialized on 29 July, SM falls below the stress threshold and a smart irrigation is needed. In this case, according to the observed
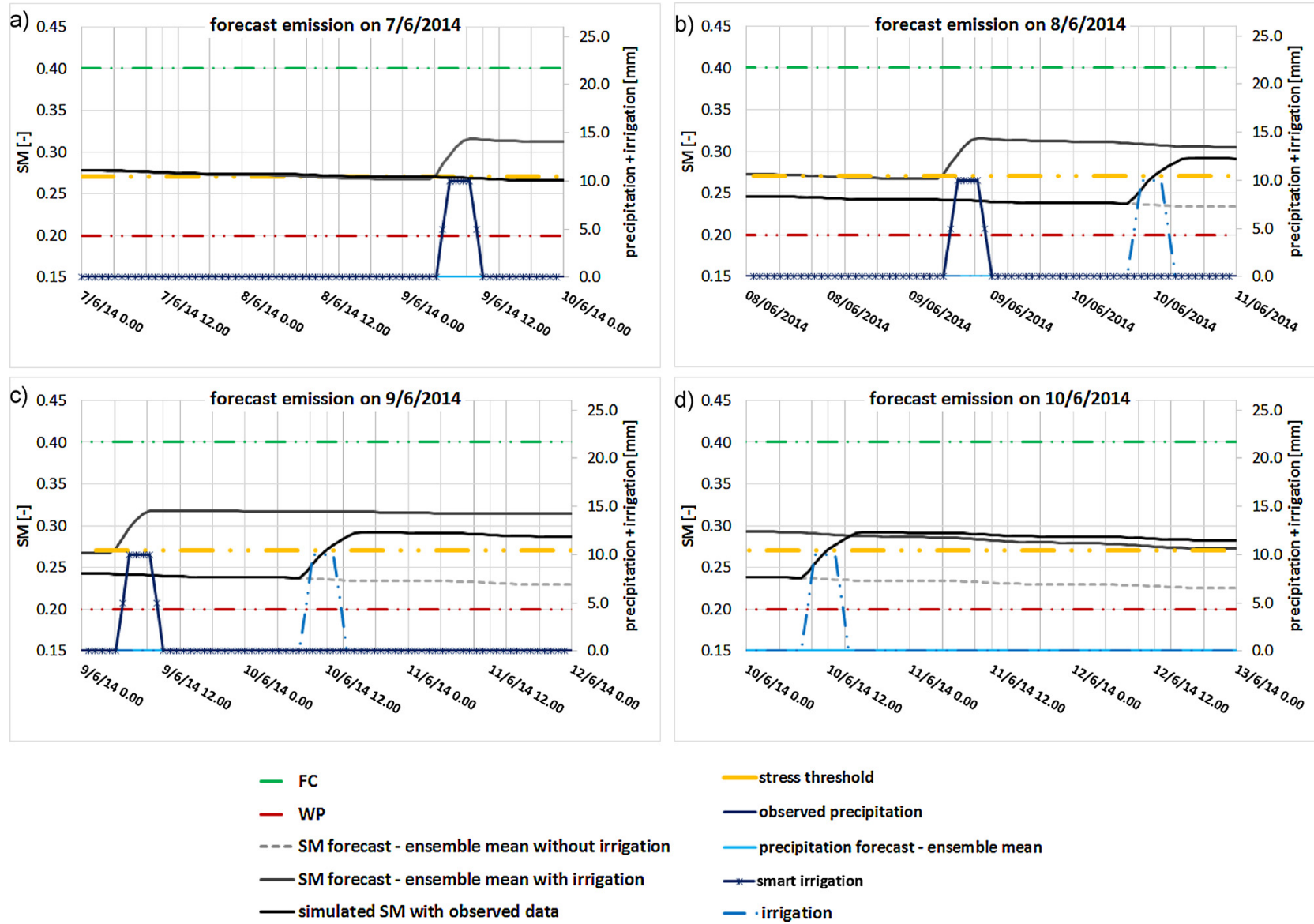

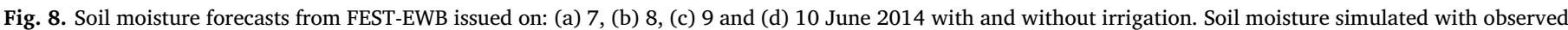

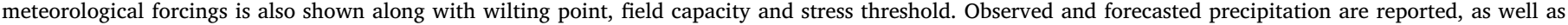
observed irrigation and the smart irrigation. 

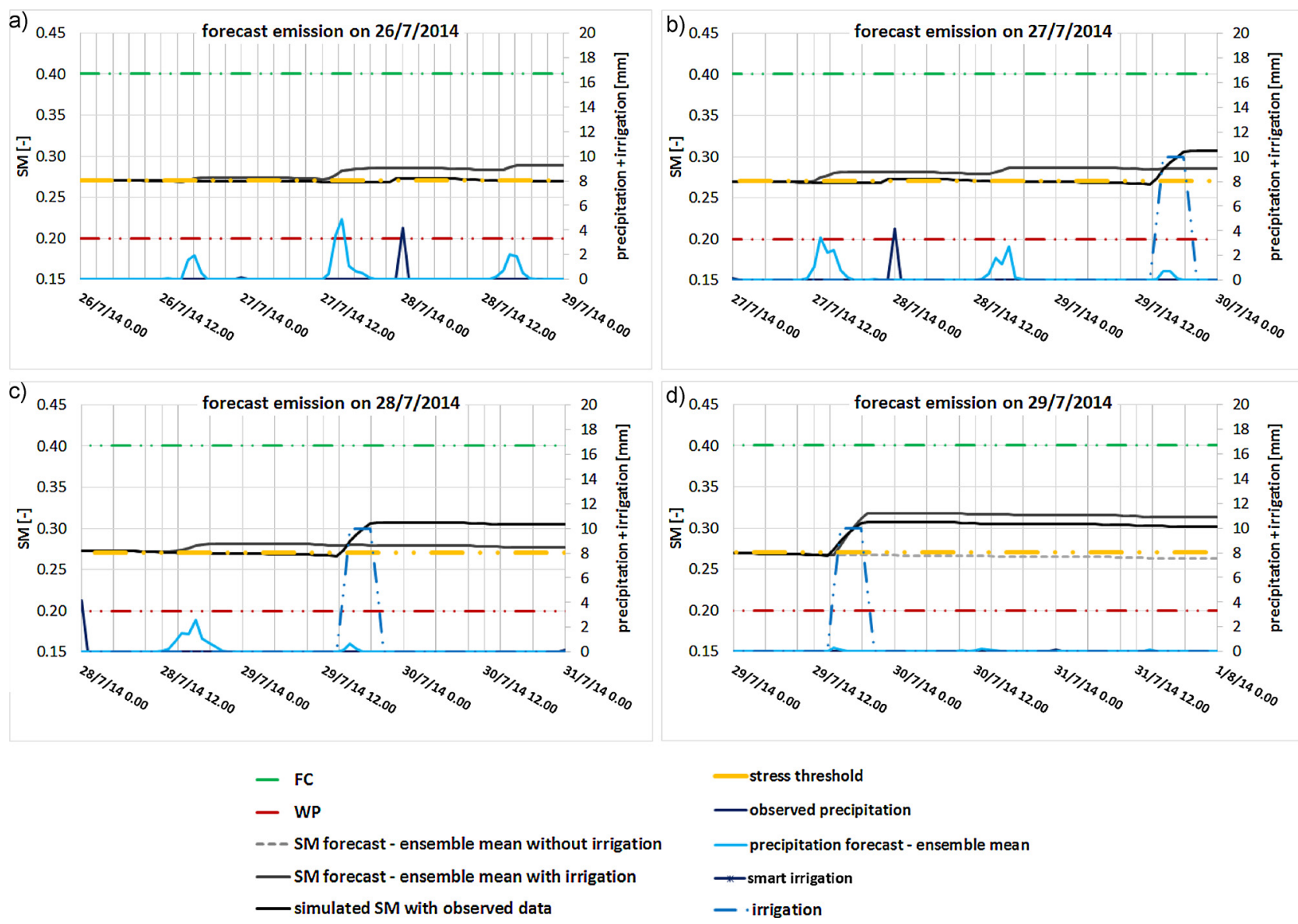

Fig. 9. Soil moisture forecasts from FEST-EWB issued on (a) 26, (b) 27, (c) 28 and (d) 29 July 2014 with and without irrigation. Soil moisture simulated with observed meteorological forcings is also shown along with wilting point, field capacity and stress threshold. Observed and forecasted precipitation are reported, as well as observed irrigation and the smart irrigation.

SM values, the irrigation really occurred on 29 July and it shouldn't have been avoided, as also confirm by the meteo-hydrological system which performed correctly. Hence, the real irrigation and the smart one coincide.

In Fig. 10, soil moisture dynamic is reported either following or not the meteo-hydrological forecasts between 22-27 August 2014. Due to the almost absence of rainfall, simulated SM with forecasted and observed meteorological data are similar and are falling below the stress threshold on 24 August. The irrigation has been really performed on this date. Hence, the system advice was correct.

These comparisons allowed computing the performances of the whole implemented system. It is interesting to note that the three irrigations that actually took place never raised the soil water content above the surplus threshold, showing already a general parsimonious water management by the farmer.

\section{Discussion and conclusion}

The paper discussed advances in coupling satellite driven soil water balance model and meteorological forecast as support for smart farming and in particular efficient irrigation for an operative farm in the South of Italy where semi-arid climatic conditions hold from November 2013 to September 2014.

The results show that operative applications of parsimonious irrigation are feasible by integrating satellite data for hydrological model state update and parameterization and meteorological forecasts, improving the management of the irrigation scheduling.

In particular, the reliability of the developed tool has been discussed analyzing two main issues: the calibration of the FEST-EWB energy water balance model with satellite or near sensing land surface temperatures; the accuracy of meteorological forecast and their effect on the soil moisture forecast.

Remote sensing data of LAI, fractional cover, albedo and land surface temperature have been retrieved from LANDSAT 8 with good accuracy respect to ground data. The results showed that FEST-EWB soil surface parameters calibration should be done with satellite LST in soil controlled ET fluxes, if the hydrological model has LST as principal state variable. After the calibration procedure, RMSE between RET and LANDSAT LST is equal to $1.8{ }^{\circ} \mathrm{C}$ and AMBE to $1.9{ }^{\circ} \mathrm{C}$. These errors are acceptable according to literature (Jia et al., 2003; Cammalleri et al., 2012). The accuracy of remotely sensed LST should be also considered due to the retrieval algorithm, to the definition of satellite LST over heterogeneous area and to the atmospheric correction.

Then, the paper showed that reliable soil moisture forecasts can be obtained with a mean relative error of less than $10 \%$, even though the accuracy of the forecasted meteorological variables is lower especially for air temperature and incoming shortwave radiation whose relative error can reach $30 \%$. This may be related to the high non linearity of the hydrological model processes that allow that the meteorological forcings errors are not linearly propagated. This is particularly true for soil moisture, which has a slow dynamic and doesn't have a daily cycle. An immediate effect on SM is only visible when precipitation is fore-casted. Instead, energy fluxes and LST estimates are strongly affected by the differences between meteorological forecasts and observation due to their instantaneous response to external forcings. Moreover, the hydrological model forced by the WRF forecasts performs well when there are essentially no precipitation events (June and August cases). That is, the calibration of vegetation, albedo, and LST improves the 

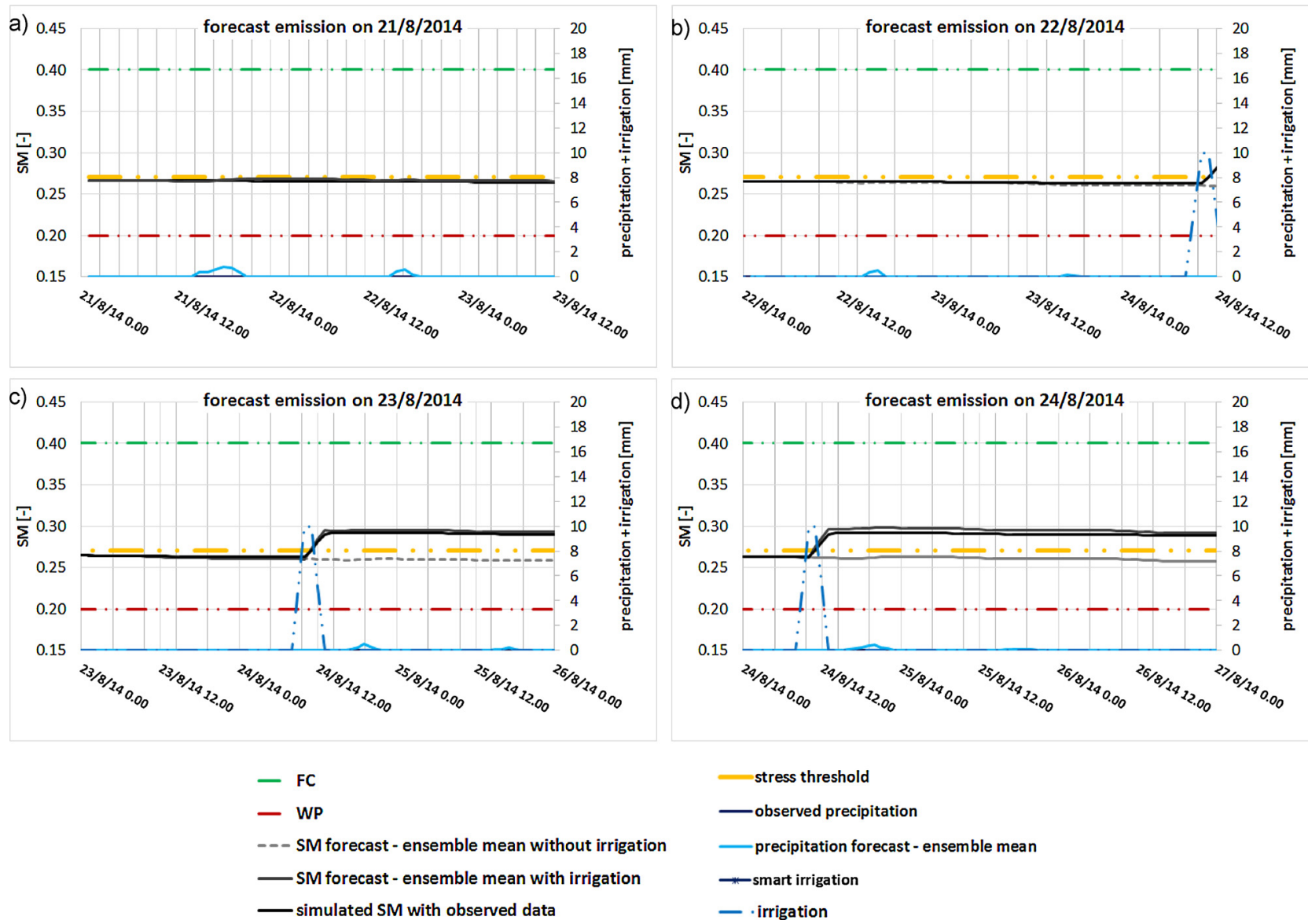

Fig. 10. Soil moisture forecasts from FEST-EWB issued on (a) 21, (b) 22, (c) 23 and (d) 24 August 2014 with and without irrigation. Soil moisture simulated with observed meteorological forcings is also shown along with wilting point, field capacity and stress threshold. Observed and forecasted precipitation are reported, as well as observed irrigation and the smart irrigation.

initial conditions and the representation of the water and energy exchanges during dry down periods so that the modeling system performs well during these times. However, during periods that feature rain events (July), where soil moisture is controlled primarily by the location and timing of the rain events, the errors in the WRF precipitation forecasts make the system less reliable.

SM forecast was reasonably satisfactory and the results showed how combing meteorological and hydrological model that were correctly calibrated, it was possible to get reliable SM forecasts for up to 3 days, and this helped farmers to properly decide irrigation scheduling. However, the definition of stress threshold that regulates the irrigation timing should be probably defined with confidence bands to consider the uncertainty embedded in the whole modeling procedure.

Finally, the developed methodology has been shown for a single field, but due to the intrinsic characteristic of the satellite data, hydrological model and meteorological forecast to be distributed in space, this approach can be exported to larger areas from a single farm to irrigation consortium for managing water resources.

\section{Acknowledgement}

This work was supportedby SIM project "Smart Irrigation from Soil Moisture Forecast Using Satellite and Hydro-Meteorological Modelling" [http://www.sim.polimi.it], funded by the Ministry for Education, University and Research of Italy within the EU Water Joint Programming Initiative. A special thanks to Stefano and Paolo Guzzetti, Luigi Corbari from Guzzetti Farm for hosting the field measurements and for helping in maintaining the eddy covariance station. Thanks to Borutti R. and Brognoli G. who contributed in elaborating some data.

\section{References}

Allen, R.G., Pereira, L.S., Raes, D., Smith, M., 1998. Crop evapotranspiration guidelines for computing crop water requirements. FAO irrigation and drainage paper 56. Rome, Italy. .

Anderson, M.C., Morse, A., Kustas, W.P., 2012. Use of Landsat thermal imagery in monitoring evapotranspiration and managing water resources. Remote Sens. Environ. 122, 50-65.

Barsi, J.A., Schott, J.R., Palluconi, F.D., Hook, S.J., 2005. Validation of a web-based atmospheric correction tool for single thermal band instruments. Earth Observing Systems X, Proc. SPIE Vol. 5882.

Bastiaanssen, W.G.M., Molden, D.J., Makin, J.W., 2000. Remote sensing for irrigated agriculture: examples from research and possible applications. Agric. Water Manage 46, 137-155.

Bastiaanssen, W., Noordman, E., Pelgrum, H., Davids, G., Thoreson, B., Allen, R., 2005. SEBAL model with remotely sensed data to improve water-resources management

under actual field conditions. J. Irrig. Drain Eng. 131:1 (85), 85-93.

Bausch, W.C., 1995. Remote sensing of crop coefficients for improving the irrigation scheduling of corn. Agric. Water Manage. 27, 55-68.

Belmonte, A.C., Jochum, A.M., GarcÍa, A.C., Rodríguez, A.M., Fuster, P.L., 2005. Irrigation management from space: towards user-friendly products. Irrig. Drain. 19

(3), 337-353.

Berthet, L., Andréassian, V., Perrin, C., Javelle, P., 2009. How crucial is it to account for the antecedent moisture conditions in flood forecasting? Comparison of event-based and continuous approaches on 178 catchments. Hydrol. Earth Syst. Sci. 13 (6), 819831 .

Cabelguenne, M., Debaeke, P., Puech, J., Bosc, N., 1997. Real time irrigation management using the EPICPHASE model and weather forecasts. Agric. Water. Manage. 32 (3), 227-238.

Cai, J., Liu, Y., Lei, T., Santos Pereira, L., 2007. Estimating reference evapotranspiration with the FAO Penman-Monteith equation using daily weather forecast messages. Agric. Forest Meteor. 145, 22-35.

Cammalleri, C., Ciraolo, G., La Loggia, G., Maltese, A., 2012. Daily evapotranspiration assessment by means of residual surface energy balance modeling: a critical analysis under a wide range of water availability. J. Hydrol. 452-453, 119-129.

Casa, R., Rossi, M., Sappa, G., Trotta, A., 2009. Assessing crop water demand by remote sensing and GIS for the pontina plain, Central Italy. Water Resour. Manag. 23 (9), 
$1685-1712$

Ceppi, A., Ravazzani, G., Corbari, C., Salerno, R., Meucci, S., Mancini, M., 2014. Real time drought forecasting system for irrigation management. Hydrol. Earth Syst. Sci. 18, 3353-3366.

Consoli, S., Stagno, F., Roccuzzo, G., Cirelli, G.L., Intrigliolo, F., 2014. Sustainable management of limited water resources in a young orange orchard. Agric. Water. Manage 132, 60-68.

Corbari, C., Mancini, M., 2014. Calibration and validation of a distributed energy water balance model using satellite data of land surface temperature and ground discharge measurements. J. Hydrometeor. 15, 376-392.

Corbari, C., Ravazzani, G., Mancini, M., 2011. A distributed thermodynamic model for energy and mass balance computation: FEST-EWB. Hydrol. Process. 25, 1443-1452.

Corbari, C., Masseroni, D., Mancini, M., 2012. Effetto delle correzioni dei dati misurati da stazioni eddy covariance sulla stima dei flussi evapotraspirativi. Ital. J. Agrometeorol 1, 35-51.

Corbari, C., Sobrino, J.A., Mancini, M., Hidalgo, V., 2013. Mass and energy flux estimates at different spatial resolutions in a heterogeneous area through a distributed en-ergywater balance model and remote-sensing data. Int. J. Remote Sens. 34 (9-10), 32083230.

Corbari, C., Mancini, M., Li, J., Su, Z., 2015. Can satellite land surface temperature data be used similarly to ground discharge measurements for distributed hydrological model calibration? Hydrol. Sciences J. 60 (1-2), 202-217.

Crow, W.T., Wood, E.F., Pan, M., 2003. Multiobjective calibration of land surface model evapotranspiration predictions using streamflow observations and spaceborne surface radiometric temperature retrievals. J. Geophys. Res.-Atmos. 108 (D23).

D'Urso, G., Menenti, M., 1995. Mapping crop coefficients in irrigated areas from landsat TM images. Engman, E.T., Guyot, G., Marino, C.M. (Eds.), Proc. SPIE 2585, Remote Sensing for Agriculture, Forestry, and Natural Resources 41-47.

D’Urso, G., Richter, K., Calera, A., Osann, M.A., Escadafal, R., Garatuza- Pajan, J., et al., 2010. Earth Observation products for operational irrigation management in the context of the PLEIADeS project. Agric. Water Manag. 98, 271-282.

Detto, M., Montaldo, N., Albertson, J.D., Mancini, M., Katul, G., 2006. Soil moisture and vegetation controls on evapotranspiration in a heterogeneous Mediterranean ecosystem on Sardinia, Italy. Water Resour. Res. 42, W08419.

Dooge, J.C.I., 1986. Looking for hydrologic laws. Water Resour. Res. 22 (9), 46-58.

EEA. Water resources across Europe-confronting water scarcity and drought. European Environmental Agency Report No 2/2009. 55

Foken, T., 2008. Micrometeorology. Springer, Berlin 306 pp.

Forrest, S.M., Johnson, L.F., Lund, C.P., Pierce, L.L., Michaelis, A.R., Hiatt, S.H., Guzman, A., Adhikari, D.D., Purdy, A.J., Rosevelt, C., Votava, P., Trout, T.J., Temesgen, B., Frame, K., Sheffner, E.J., Nemani, R.R., 2012. Satellite irrigation management support with the terrestrial observation and prediction system: a framework for integration of satellite and surface observations to support improvements in agricultural water resource management. IEEE J. S. T. Appl. EO Remote Sens. 5 (6)

Franks, S.W., Beven, K.J., 1999. Conditioning a multiple patch SVAT model using uncertain space-time estimates of surface fluxes as inferred from remotely sensed data.

Water Resour. Res. 35 (9), 2751-2761.

Gowing, J.W., Ejieji, C.J., 2001. Real-time scheduling of supplemental irrigation for potatoes using a decision model and short term weather forecasts. Agric. Water Manage. 47, 137-153.

Gutmann, E.D., Small, E.E., 2010. A method for the determination of the hydraulic properties of soil from MODIS surface temperature for use in land surface models.

Water Resour. Res. 46, W06520.

Hsieh, C., Katul, G., Chi, T., 2000. An approximate analytical model for footprint estimation of scalar fluxes in thermally stratified atmospheric flows. Adv. Water Resour. 23, 765-772.

Immerzeel, W.W., Droogers, P., 2008. Calibration of a distributed hydrological model based on satellite evapotranspiration. J. Hydrol. 349, 411-424.

Ingwersen, J., Steffens, K., Högy, P., Warrach-Sagi, K., Zhunusbayeva, D., Poltoradnev, M., Gäbler, R., Wizemann, H.-D., Fangmeier, A., Wulfmeyer, V., Streck, T., 2011 Comparison of Noah simulations with eddy covariance and soil water measurements at a winter wheat stand. Agric. Forest Meteor. 151 (3), 345-355 15.

Jarvis, P.G., 1976. The interpretation of the variations in leaf water potential and stomatal conductance found in canopies in the field. Philos. Trans. R. Soc. B. 273,
593-610.

Jensen, A.L., Thysen, I., 2003. Agricultural information and decision support by sms. EFITA Conference.

Jia, L., Su, Z., Van den Hurk, B., Menenti, M., Moene, A., De Bruin, H., Baselga Yrisarry, J.J., Ibanez, M., Cuesta, A., 2003. Estimation of sensible heat flux using the Surface Energy Balance System (SEBS) and ATSR measurements. Phys. Chem. Earth 28, 7588.

Jiménez-Muñoz, J.C., Cristóbal, J., Sobrino, J.A., Sòria, G., Ninyerola, M., Pons, X., 2009 Revision of the single-channel algorithm for land surface. IEEE Trans. Geosci. Remote Sens 47 (1), 339-349.

Ke, Y., Im, J., Park, S., Gong, H., 2016. Downscaling of MODIS one kilometer evapotranspiration using Landsat- 8 data and machine learning approaches. Remote Sens. 8 (215), 1-26.

Kitanidis, P.K., Bras, R.L., 1980. Real-time forecasting with a conceptual hydrologic model: analysis of uncertainty. Water Resour. Res. 16 (6), 1025-1033.

Kustas, W.P., Li, F., Jackson, T.J., Pruger, J.H., MacPherson, J.I., Wolden, M., 2004 Effects of remote sensing pixel resolution on modeled energy flux variability of croplands in Iowa. Remote Sens. Environ. 92 (4), 535-547.

Liang, S., 2000. Narrowband to broadband conversions of land surface albedo I algorithms. Remote Sens. Environ. 76, 213-238.

Mancini, M., 1990. La modellazione distribuita della risposta idrologica: effetti della variabilità spaziale e della scala di rappresentazione del fenomeno dell'assorbimento. $\mathrm{PhD}$ thesis. Politecnico di Milano, Milan, Italy in italian.

Matthew, M.W., Adler-Golden, S.M., Berk, A., Richtsmeier, S.C., Levine, R.Y., Bernstein, L.S., Acharya, P.K., Anderson, G.P., Felde, G.W., Hoke, M.P., Ratkowski, A., Burke, H.-H., Kaiser, R.D., Miller, D.P., 2000. Status of atmospheric correction using a MODTRAN4-based algorithm. SPIE Proceeding, Algorithms for Multispectral, Hyperspectral, and Ultraspectral Imagery VI 4049, 199-207.

Pappenberger, F., Ramos, M.H., Cloke, H.L., Wetterhall, F., Alfieri, L., Bogner, K., Mueller, A., Salamon, P., 2015. How do I know if my forecasts are better? Using benchmarks in hydrological ensemble prediction. J. Hydrol. 522, 697-713.

Pelosi, H., Medinac, P., Villani, G., D’Urso, G., Chirico, B., 2016. Probabilistic forecasting of reference evapotranspiration with a limited area ensemble prediction system. Agric. Water Manage. 178, 106-118.

Rabuffetti, D., Ravazzani, G., Corbari, C., Mancini, M., 2008. Verification of operational Quantitative Discharge Forecast (QDF) for a regional warning system - the AMPHORE case studies in the upper Po River. Nat. Hazard Earth Sys. 8, 161-173.

Rawls, W.J., Brakensiek, D.L., 1985. Prediction of Soil Water Properties for Hydrologic Modelling. Watershed Management in the Eighties. ASCE, pp. 293-299. Refsgaard, J.C., 1997. Parameterisation, calibration and validation of distributed hydrological models. J. Hydrol. 198, 69-97.

Richter, K., Timmermans, W.J., 2009. Physically based retrieval of crop characteristics for improved water use estimates. Hydrol. Earth Syst. Sci. 13 (5), 663-674.

Roerink, G.J., Bastiaanssen, W.G.M., Chambouleyron, J., Menenti, M., 1997. Relating crop water consumption to irrigation water supply by remote sensing. Water Resour. Manag. 11 (6), 445-465.

Saxton, K.E., Rawls, W.J., Romberger, J.S., Papendick, R.I., 1986. Estimating generalized soil water characteristics from texture. Trans. ASAE 50, 1031-1035.

Su, Z., 2002. The Surface Energy Balance System (SEBS) for estimation of turbulent heat fluxes. Hydrol. Earth Syst. Sci. 6 (1), 85-100.

Sun, S.F., 1982. Moisture and Heat Transport in a Soil Layer Forced by Atmospheric Conditions. M.Sc. Thesis. University of Connecticut, Storrs.

Thom, A.S., 1975. Momentum, mass and heat exchange of plant communities. In: Monteith, J.L. (Ed.), Vegetation and Atmosphere. Academic Press, pp. 57-110.

Twine, T.E., Kustas, W.P., Norman, J.M., Cook, D.R., Houser, P.R., Meyers, T.P., Prueger, J.H., Starks, P.J., Wesely, M.L., 2000. Correcting eddy-covariance flux underestimates over a grassland. Agric. Forest Meteor. 103, 279-300.

Venaläinen, A., Salo, T., Fortelius, C., 2005. The use of numerical weather forecast mode predictions as a source of data for irrigation modeling. Meteorol. Appl. 12, 307-318. Zappa, M., Jaun, S., Germann, U., Walser, A., Fundel, F., 2011. Superposition of three sources of uncertainties in operational flood forecasting chains. Atmos. Res. 100, 246-262.

Zucaro, R., 2014. Atlas of Italian irrigation systems. Istituto Nazionale di Economia Agraria (INEA). 